\title{
Divergence with gene flow and fine-scale phylogeographical structure in the wedge-billed woodcreeper, Glyphorynchus spirurus, a Neotropical rainforest bird
}

\author{
B. MILÁ,*†‡ R. K. WAYNE, ${ }^{*} \ddagger$ P. FITZE† and T. B. SMITH* \\ ${ }^{*}$ Center for Tropical Research, Institute for the Environment, University of California, 619 Charles Young Dr., Los Angeles, CA \\ 90095-1496, USA, +Museo Nacional de Ciencias Naturales, CSIC, Madrid 28006, Spain, łDepartment of Ecology and \\ Evolutionary Biology, University of California, 621 Charles Young Dr., Los Angeles, CA 90095, USA
}

\begin{abstract}
Determining the relative roles of vicariance and selection in restricting gene flow between populations is of central importance to the evolutionary process of population divergence and speciation. Here we use molecular and morphological data to contrast the effect of isolation (by mountains and geographical distance) with that of ecological factors (altitudinal gradients) in promoting differentiation in the wedge-billed woodcreeper, Glyphorynchus spirurus, a tropical forest bird, in Ecuador. Tarsus length and beak size increased relative to body size with altitude on both sides of the Andes, and were correlated with the amount of moss on tree trunks, suggesting the role of selection in driving adaptive divergence. In contrast, molecular data revealed a considerable degree of admixture along these altitudinal gradients, suggesting that adaptive divergence in morphological traits has occurred in the presence of gene flow. As suggested by mitochondrial DNA sequence data, the Andes act as a barrier to gene flow between ancient subspecific lineages. Genome-wide amplified fragment length polymorphism markers reflected more recent patterns of gene flow and revealed fine-scale patterns of population differentiation that were not detectable with mitochondrial DNA, including the differentiation of isolated coastal populations west of the Andes. Our results support the predominant role of geographical isolation in driving genetic differentiation in G. spirurus, yet suggest the role of selection in driving parallel morphological divergence along ecological gradients.
\end{abstract}

Keywords: adaptive divergence, AFLP, altitudinal gradient, ecomorphology, gene flow, mtDNA, phylogeography

Received 25 October 2008; revision received 7 April 2009; accepted 9 April 2009

\section{Introduction}

Patterns of intraspecific geographical variation in phenotypic traits and genetic markers provide insight into the factors driving population differentiation and ultimately speciation (Avise 2000; Schluter 2000; Coyne \& Orr 2004). In heterogeneous landscapes, restrictions in gene flow between populations can be caused not only by geographical barriers or isolation by distance (Ribera \& Vogler 2004; Knowles \& Richards 2005), but also by

Correspondence: Borja Milá, Fax: +34 915645078;

E-mail: bmila@mncn.csic.es nonvicariant factors such as natural selection acting on fitness traits when environmental conditions and selective regimes differ sufficiently between locales (Rice \& Hostert 1993; Schluter 2001; Rundle \& Nosil 2005; Hedrick 2006; Hoekstra 2006; Niemiller et al. 2008; Nosil et al. 2008).

In tropical latitudes characterized by high species diversity, a large body of evidence supports the major role of allopatric factors in driving speciation (Haffer 1969; Mayr \& O’Hara 1986; Fjeldså \& Lovett 1997; Roy et al. 1997; García-Moreno \& Fjeldså 2000; Moritz et al. 2000). An alternative to these allopatric models are those that emphasize the role of natural selection along 
ecological gradients between parapatric populations (Endler 1977, 1982; Gentry 1989; Smith et al. 1997; Schneider \& Moritz 1999; Schneider et al. 1999), and an increasing number of empirical studies in a wide array of taxa have documented the role of selection in promoting phenotypic differentiation in the presence of gene flow along ecological gradients between parapatric populations, an important step in divergence-withgene-flow models of ecological speciation (Knox \& Palmer 1995; Smith et al. 1997, 2005, 2008; Orr \& Smith 1998; Schneider et al. 1999; Ogden \& Thorpe 2002; Petren et al. 2005; Nosil et al. 2008). The relative contribution of neutral and adaptive factors in differentiating populations as well as the interaction between these two forces is of fundamental importance to understanding the evolutionary mechanisms of diversification.

The bird fauna of tropical South America is the richest in the world (Stotz et al. 1996), yet the evolutionary mechanisms generating and maintaining such diversity remain poorly understood. A recent and growing emphasis on intraspecific phylogeography using mitochondrial DNA (mtDNA) variation across species ranges is providing a better picture of differentiation at the population level (Marks et al. 2002; Aleixo 2004; GarcíaMoreno et al. 2004; Cheviron et al. 2005; Pérez-Emán 2005; Dingle et al. 2006; Cabanne et al. 2007; Cadena et al. 2007; Nyári 2007; Puebla-Olivares et al. 2008) although interpretation of emerging patterns has typically been restricted to the role of historical vicariant factors over relatively large geographical and temporal scales.

Attempts to investigate the actual evolutionary mechanisms underlying divergence and speciation in Neotropical birds are scarce (Brumfield et al. 2001; Brumfield 2005; Chaves et al. 2007). Here we investigate the role of vicariant and ecological factors in driving morphological and genetic differentiation in the wedge-billed woodcreeper (Glyphorynchus spirurus), a widespread and common understory bird found in rainforests from Mexico to South America (Restall et al. 2006). In Ecuador, the species ranges from the tropical lowlands to about $1500 \mathrm{~m}$ in elevation up the Andean foothills, an altitudinal range that spans significant change in environmental conditions and forest structure (Ridgely \& Greenfield 2001). The species is relatively continuously distributed east of the Andes, whereas the distribution on the west side is more fragmented, with populations in coastal mountain ranges along the Pacific coast (e.g. Chongón-Colonche and Mache-Chindul mountains) being isolated from Andean populations (Ridgely \& Greenfield 2001; Buermann et al. 2008). This distributional pattern is thus suitable for contrasting differentiation by means of isolation by distance in continuous populations, differentiation in small isolated populations, and selection-driven divergence along ecological gradients.
To examine morphological variation, we analysed field measurements of various morphological traits to find associations between morphology and ecological variables. The morphological traits measured may reflect three main selective forces known to be important in birds and likely to be relevant to woodcreepers: foraging efficiency, flight efficiency and Bergmann's rule (the tendency to increase in size in colder climates; (Zink \& Remsen 1986). If drift has played a major role in shaping morphological traits, then differences between populations on either side of the Andes should be equivalent to those found in neutrally evolving genetic markers. Alternatively, if directional selection has been mainly responsible for driving morphological change, then individuals in similar environments on different sides of the Andes should be morphologically more similar than individuals in different environments on the same side.

Two types of molecular data were used to examine genetic variation in G. spirurus: mtDNA sequence data and amplified fragment length polymorphism (AFLP) markers. Patterns of gene flow and historical demography were inferred from genetic distances among individuals and populations, phylogenetic analyses, and Bayesian inference of population structure.

\section{Materials and methods}

\section{Field procedures and habitat measurements}

Birds were captured using standard mist nets at 16 sampling localities (Fig. 1 and Supporting Information). Individuals were aged using plumage characteristics and the degree of skull ossification (Pyle 1997). Sex determination was carried out in the laboratory by means of a polymerase chain reaction (PCR) test using primers MSZ1R (Sehgal et al. 2005) and 2550F (Fridolfsson \& Ellegren 1999). Individuals were weighed and marked permanently with a uniquely numbered aluminium band. A wing ruler was used to measure the unflattened wing chord (the distance from the carpal joint to the tip of the longest primary) to the nearest $0.5 \mathrm{~mm}$. Dial callipers of $0.1-\mathrm{mm}$ precision were used to measure tail length (from the uropygial gland to the tip of the longest rectrix), tarsus length (from the intertarsal joint to the most distal undivided scute on the tarsometatarsus), bill length (from the base of the bill at the cranium to the tip of the upper mandible), and bill width and depth (both measured at the anterior end of the nares). All measurements were taken by BM.

At 10 sampling localities, we estimated tree density, tree size and moss cover on tree bark. We collected the following data at a minimum of 10 points per locality, separated $30 \mathrm{~m}$ along the mist-netting trail and located 


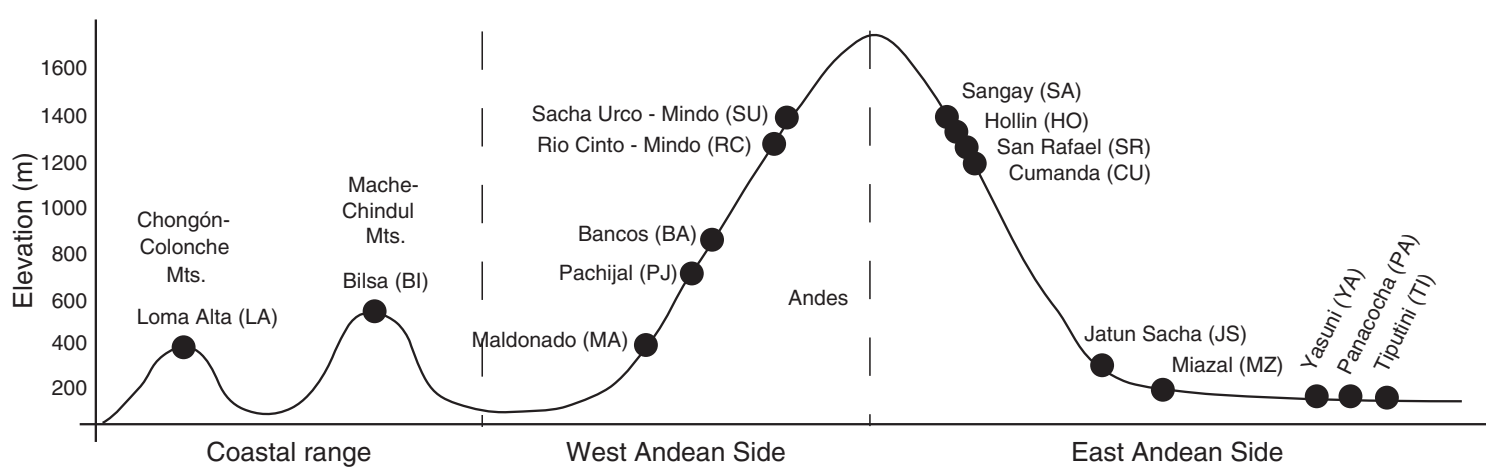

Fig. 1 Altitudinal distribution of sampling sites on both sides of the Andes. See Fig. 4 for a two-dimensional overhead depiction of sampling localities.

$10 \mathrm{~m}$ off the trail in a random perpendicular direction: in a circle of 5-m radius, each tree with a diameter at breast height $(\mathrm{DBH})$ above $10 \mathrm{~cm}$ was counted, measured with a DBH tape, and visually assigned a mosscover value. The moss-cover value ranged from 0 (no moss) to 10 (completely covered by moss) and was scored in a $50-\mathrm{cm}$ band around the tree at breast height. Moss and DBH data were collected on a total of 1174 trees measured at 113 points in 10 different locations (BI, LA, SU, RC, MA, BA, HO, CU, SA and TI; Fig. 1), spanning the entire altitudinal gradient on both slopes. A single observer (BM) estimated moss cover on all trees.

To analyse moss abundance, we run a mixed model analysis of covariance (ANCOVA) with Andean side, elevation and their interaction as fixed effects. Nonindependence of abundance data gathered at different localities and points was accounted for by entering locality, and point nested in locality, as random effects into the model. Prior to analysis, moss abundance was angular transformed to meet the assumptions of the applied models (Sokal \& Rohlf 1981).

For the analyses of tree density, we first calculated average tree density for each sampling point $(n=113)$ and run a mixed model ANCOVA with Andean side, elevation and the interaction as fixed effects, and locality as random effect. Prior to analysis, tree density was transformed to meet the model assumptions (transformed density $=$ density $^{0.2}$ ).

\section{Morphological analysis}

We analysed variation in morphological traits along the gradient by means of a generalized linear model (GLM) with Andean side (east vs. west) and sex as fixed factors, and elevation and structural body size (see below) as covariates. For testing Bergmann's rule, we used structural body size as the dependent variable. In order to account for the nonindependence of individual measurements within a locality, we entered population (sampling site) as a random factor in both analyses. Nonsignificant parameters were backward eliminated until the best model was obtained.

Structural body size was assessed by means of a principal components analysis (PCA) on the correlation matrix of six morphological traits (wing length, tail length, tarsus length, bill length, bill width and bill depth). The PCA yielded high factor loadings on the first principal component (Table S1), and PC1 values were subsequently used as an index of overall size and introduced as a covariate in the GLM. To avoid statistical dependency between the dependent variable and the PC1, we ran separate PCAs. In these analyses, we run a PCA with all covariates except the dependent variable, and used the resulting PC1 as the covariate in the GLM to run the model on the dependent variable.

Only adult individuals of known sex were used. Adults were defined as those individuals that had undergone at least one complete basic (postnuptial) moult (i.e. were at least 1 year old) and had thus attained full size in morphological traits at the time of capture. Some of the variables were transformed prior to analyses to meet model assumptions. Model assumptions such as normality of the residuals and homogeneity of variances were met for all presented models. Significance levels were two-tailed.

Morphological divergence among sites was computed as the Euclidean distance between population mean values of normalized measurements following Smith et al. (2005).

\section{$m t D N A$ sequencing and analysis}

We extracted genomic DNA from blood samples using a Qiagen $^{\mathrm{TM}}$ extraction kit and followed the recommended protocol. We used the PCR to amplify $639 \mathrm{bp}$ of the NADH dehydrogenase subunit 2 (ND2) gene with primers L5216 and H6313 (Sorenson et al. 1999). PCR cycles were as follows: 3-min denaturation at 
$94{ }^{\circ} \mathrm{C}$ followed by 36 cycles of $94{ }^{\circ} \mathrm{C}$ for $30 \mathrm{~s}, 50{ }^{\circ} \mathrm{C}$ for $45 \mathrm{~s}$, and $72{ }^{\circ} \mathrm{C}$ for $45 \mathrm{~s}$, with a final extension of $5 \mathrm{~min}$ at $72{ }^{\circ} \mathrm{C}$. Products were purified with an Ultra-Clean ${ }^{\mathrm{TM}}$ (MoBio Labs.) PCR purification kit and run in a dydeoxy-terminator cycle-sequencing reaction using a CEQ cycle sequencing kit by Beckman-Coulter. Products of this reaction were purified with an ethanol precipitation and sequenced in a Beckman-Coulter CEQ 2000 automated sequencer. Sequences were automatically aligned using Sequencher 4.1. (GeneCodes) and variable sites were checked visually for accuracy. Sequences were unambiguously translated into their amino acid sequence and no double peaks were observed. All unique sequences used in this study have been deposited in GenBank under Accession nos FJ848676FJ848704.

Population structure was deduced with an analysis of molecular variance (AMOVA) using Arlequin 3.1 (Excoffier et al. 2005). AMOVA uses the frequencies of haplotypes and the number of mutations among them to test the significance of the variance components associated with various hierarchical levels of genetic structure (within populations, among populations within groups, and among groups) by means of nonparametric permutation methods (Excoffier et al. 1992). We generated a matrix of $F_{\mathrm{ST}^{-}}$-values among populations and tested for differentiation between groups with an exact test of population differentiation (Raymond \& Rousset 1995a) using 10000 Markov chain steps in Arlequin 3.1.

To test for past sudden changes in effective population size, we used Fu's $F_{\mathrm{s}}$-test of neutrality ( $\mathrm{Fu} 1997$ ), which detects departures from neutrality in scenarios characterized by an excess of rare alleles and young mutations in nonrecombining sequences. We used Arlequin 3.1 to generate values of $F_{\mathrm{s}}$ and interpreted significant and large negative values of $F_{\mathrm{s}}$ as an excess of recent mutations indicating a recent expansion in population size (Fu 1997; Ramos-Onsins \& Rozas 2002). To test the premise that variation in the ND2 gene is selectively neutral, we conducted a McDonald-Kreitman test (McDonald \& Kreitman 1991) by comparing the eastern and western Andean lineages of Glyphorynchus spirurus in the program DnaSP (Rozas et al. 2003). The test compares the ratio of fixed synonymous (SF) to replacement (RF) substitutions to the ratio of polymorphic synonymous (SP) to replacement (RP) substitutions and uses a two-tailed Fisher's exact test to detect significant departures from neutrality.

A phylogeny of ND2 haplotypes using Bayesian analysis was constructed with MrBayes v. 3.1.2 (http:// mrbayes.csit.fsu.edu/) (Huelsenbeck et al. 2001) using the model of sequence evolution that best fit the data (GTR+G) according to MrModelTest (Nylander 2004), and partitioning sites by codon position. Two Markov chains were run simultaneously for 2 million generations and sampled every 100 generations. Trees generated prior to stationarity were excluded, and a consensus topology was obtained from the last 30001 trees in the chain. We confirmed Markov chain Monte Carlo chain convergence using TRACER 1.3 (Rambaut \& Drummond 2003). We also constructed a network of haplotypes using the reduced median-joining algorithm in the program NETWORK v. 4.5.1.0 (Forster et al. 2007).

\section{AFLP profiling and analysis}

Amplified fragment length polymorphism profiles were generated using a protocol modified slightly from (Vos et al. 1995). Whole genomic DNA was digested with restriction enzymes EcoRI and MseI and fragments were ligated to oligonucleotide adapters with T4 DNA ligase. A random subsample of fragments was obtained through a preselective amplification using primers E-t and $\mathrm{M}-\mathrm{c}$, followed by three selective amplifications using primer pairs E-tag/M-cga, E-tgc/M-cga and E-tgc/M-cgt, with each E primer fluorescently labelled with 6FAM dye. Twelve pairs of selective amplification primers were tried, but only the pairs producing repeatable and unambiguously scorable profiles were used in the analysis. Selectively amplified fragments were run in an ABI 3700 genetic analyser with a LIZ500 size standard. Peaks were visualized using GeneMapper 3.7 and scored manually, with individuals and populations randomized to avoid observer bias. Only unambiguously scorable loci and individuals were included in the analysis and peaks found in $<2 \%$ of individuals were excluded. Methodological error rate was assessed by running a subset of 10 individuals twice from the preselective amplification step. The average per-locus error rate for the AFLP data, measured as recommended by Bonin et al. (2004), was $1.8 \%$, a rate comparable to that of other AFLP studies in birds (Milá et al. 2008; Smith et al. 2008).

We estimated allelic frequencies using Zhivotovsky's (1999) Bayesian method with uniform prior distributions, and Nei's distances and $F_{\mathrm{ST}}$-values where then calculated using the method by Lynch \& Milligan (1994) as implemented in the program AFLP-SURV v. 1.0 (Vekemans et al. 2002). To test for isolation by distance and to compare genetic and morphological distances, we also computed genetic distances as $F_{\mathrm{ST}} /\left(1-F_{\mathrm{ST}}\right)$ as recommended by (Rousset 1997) using GENEPOP 4.0 (Raymond \& Rousset 1995b).

To assess genetic structure among samples, we conducted a principal coordinate analysis on a genetic distance matrix generated from the binary presenceabsence matrix as implemented in GENALEx 6.0 (Peakall 
\& Smouse 2006). We also examined the patterns of population structure using the assignment probability test in the program Structure 2.2 (Pritchard et al. 2000). This program uses Bayesian inference to generate posterior probabilities of assignment of individuals to each of a given number of populations $(K)$ independently of sampling site. As recommended for dominant markers, we applied a model of no admixture with correlated allele frequencies (Pritchard \& Wen 2004) and the optimal value of $K$ was calculated following the method by Evanno et al. (2005).

Detection of loci potentially under selection was conducted by plotting $F_{\mathrm{ST}}$ against heterozygosity under the assumption of Hardy-Weinberg equilibrium to identify significant outlier loci using the program DFDIST (Beaumont \& Nichols 1996). Significance values at the $95 \%$ level for outlier loci were obtained by generating a null distribution of $F_{\mathrm{ST}^{-}}$-values based on 50000 simulated loci with a mean $F_{\mathrm{ST}}$ equivalent to the 'neutral' mean $F_{\mathrm{ST}}$ of the empirical distribution, which was obtained by trimming the $10 \%$ highest and lowest $F_{\mathrm{ST}}$-values (Beaumont \& Nichols 1996; Bonin et al. 2006).

\section{Results}

\section{Habitat variables}

There was a significant effect of elevation and Andean side on moss abundance [elevation: $F_{1,1058}=191.374$, $P<0.0001, \quad 7.6 \%$ variance explained, estimate: $0.0007 \pm 0.00005$; side: $F_{1,1058}=4.124, P=0.0425,0.2 \%$ variance explained, estimate(east): $-0.041 \pm 0.02$ ], as well as a significant interaction between elevation and side $\left[F_{1,1058}=4.399, P=0.036,0.2 \%\right.$ variance explained, estimate(east): $-0.0001 \pm 0.0005$, Fig. 2A]. There were highly significant differences between localities explaining $2.8 \%$ of the variance $\left(F_{9,103}=4.090, P<0.001\right)$, and there were no significant differences between sampling points $\left(F_{103,1058}<0.001, P=1.000\right)$. Including tree diameter as a covariate into the analysis did not change the results (interaction $F_{1,1057}=4.318, P=0.038,0.2 \%$ variance explained). With respect to tree density, there were significant differences between eastern and western Andean sides $\left[F_{1,102}=7.116, P=0.009\right.$, estimate(east): $-0.097 \pm 0.037$, Fig. 2C] but not with elevation $\left(F_{1,101}=1.545, P=0.217\right)$ and the interaction between the two was not significant $\left(F_{1,100}=0.037, P=0.848\right)$. Differences between localities were highly significant $\left(F_{9,102}=9.120, P<0.001\right)$.

\section{Variation in morphological traits}

The GLM analysis of morphological variables revealed clear spatial patterns of morphological differentiation in
Glyphorynchus spirurus. A significant effect of elevation was detected in three foraging-related traits: tarsus length, bill width and bill depth (Table 1), all of them becoming larger with elevation relative to overall body size.

Although we did not investigate the fitness consequences of these morphological differences, the close association between elevation and moss cover along the altitudinal gradient (Fig. 2A) suggests a role for moss in driving this pattern at least partially, especially with respect to tarsus length (Fig. 2B). Because moss data were only available from 10 of 16 sites and given the tight correlation between moss cover and elevation, the latter was used in the model instead of moss abundance. Substituting moss abundance for elevation in a similar model but using only the reduced number of sites for which moss data were available, provided very similar results (Table S2).

In contrast to foraging-related traits, no elevation effect was present for flight-related traits such as wing length and tail length, for which a large amount of variance was explained by sex differences and an Andean slope effect (Table 1). The highly significant differences in tree density found on each side of the Andes (about double in the west than in the east, Fig. 2C) independently of elevation, and its negative relationship with wing length (Fig. 2D), suggests that flight-related traits may be influenced by flight distance among trees rather than altitude.

Finally, structural body size (introduced in the model as the PC1 values from a PCA) explained a nonsignificant amount of variance in all traits except bill depth (3.8\%; Table 1), indicating that the observed differences in size and shape are not due to allometry. In agreement with Bergmann's rule, structural body size (represented by PC1 of all traits) showed a significant increase with elevation in a GLM (elevation: $F_{1,136}=12.311, P<0.001$, $5.64 \%$ of variance explained; sex: $F_{1,136}=54.350$, $P<0.001,24.91 \%$ of variance explained).

\section{Population genetic structure and gene flow}

$m t D N A$ variation. Sequencing of the 639-nucleotide fragment of the ND2 gene in 162 individuals resulted in 29 haplotypes sampled (54 substitution sites, 9 transversions, 45 transitions and no indels). Average absolute pairwise divergence between populations across the Andes was $44.58 \mathrm{bp}(\mathrm{SD}=0.70)$, or $6.98 \%$, and values within each side of the Andes were much lower (East: $2.61 \mathrm{bp}, \mathrm{SD}=1.93,0.41 \%$; West: $2.02 \mathrm{bp}, \mathrm{SD}=0.50$, $0.32 \%$; Table 2). Genetic differentiation across the Andes was high $\left(F_{\mathrm{ST}}=0.948, P<0.0001\right)$, and lower but significant between the coastal range and the west Andean slope $\left(F_{\mathrm{ST}}=0.088, P<0.014\right)$ (Table 2$)$. Haplotype diversity indices where relatively similar across sites 

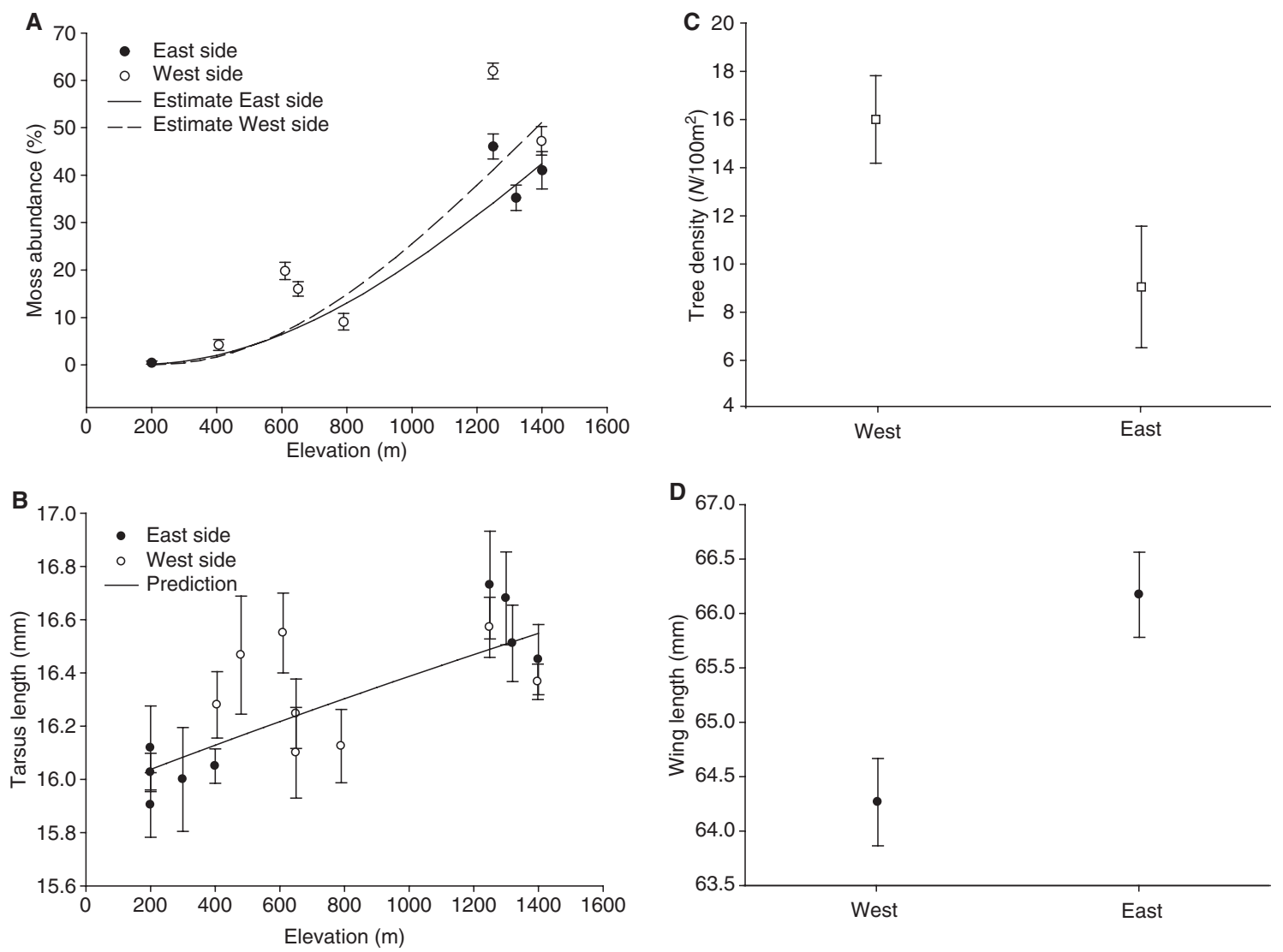

Fig. 2 Relationship between morphological traits and environmental variables in Glyphorynchus spirurus. Bars correspond to standard errors around mean values. (A) Relationship between moss abundance and elevation on both Andean sides. (B) Relationship between tarsus length and elevation. (C) Tree density on both sides of the Andes. (D) Wing length on both sides of the Andes, showing a negative relationship with tree density in (C).

except for two sites where a single haplotype was found (Jatun Sacha and Loma Alta; Table 3). Nucleotide diversity was an order of magnitude higher in Pañacocha than in other sites due to the presence of haplotypes from two widely divergent mtDNA lineages found there (see below).

A haplotype phylogeny based on Bayesian inference revealed the presence of three main clades (Fig. 3A). Two clades correspond to eastern and western sides of the Andes, and a third unresolved clade is formed by haplotypes G and G2 (sampled at Pañacocha). In order to determine the affinity of these $G$ haplotypes to those in other parts of the G. spirurus range not included in our study, we aligned our ND2 sequences to those in the study by Marks et al. (2002), available in GenBank. The alignment of our sequences (trimmed to $337 \mathrm{bp}$ to match the GenBank accessions) and those from Marks et al. (2002) revealed that our eastern clade sequences cluster with those from the Napo region of Ecuador (AY096979-82) reported in Marks et al. (2002), those in our western clade cluster with sequences from the Ecuadorian Chocó (AY096970), Panama (AY096969) and
Costa Rica (AY096966), and the G1 and G2 haplotypes cluster with sequences from the Napo region of Peru (AY096973-75).

The mtDNA data revealed a low degree of structure within either side of the Andes, with most haplotypes within each region being widespread (Fig. 4) and diverging by a single nucleotide (Fig. 3B), thus suggesting either shared ancestral polymorphism (and incomplete lineage sorting) or high levels of historical gene flow between localities. An AMOVA grouping all samples into east and west of the Andes revealed that most of the variability in mtDNA sequence variation was explained by the Andean barrier $\left(\Phi_{\mathrm{ct}}=96.48 \%\right.$, $P<0.001$ ), with a negligible amount of variance being explained by the between-populations-within-groups and between-populations components of variance $\left(\Phi_{\mathrm{sc}}=0.59 \%, P<0.001 ; \Phi_{\mathrm{st}}=2.92 \%, P<0.001\right)$. Variation within the east was explained mostly by the within-population component of variance $\left(\Phi_{\mathrm{ct}}=3.41 \%\right.$, $P=0.217 ; \quad \Phi_{\mathrm{sc}}=12.74 \%, \quad P=0.014 ; \quad \Phi_{\mathrm{st}}=83.85 \%$, $P=0.003)$ when samples were grouped into foothill and lowland groups. A similar pattern was obtained in 


\begin{tabular}{|c|c|c|c|}
\hline Trait & Effect & Test statistic & $\begin{array}{l}\text { Percentage } \\
\text { variance explained }\end{array}$ \\
\hline \multirow[t]{5}{*}{ Wing length } & Elevation & $F_{1,148}<0.000$ & \\
\hline & Side & $F_{1,148}=14.098^{* * *}$ & 3.54 \\
\hline & Sex & $F_{1,148}=171.108^{* * *}$ & 43.02 \\
\hline & Side $\times$ Sex & $F_{1,148}=6.789^{* *}$ & 1.71 \\
\hline & Body size & $F_{1,133}=2.765$ & \\
\hline \multirow[t]{5}{*}{ Tail length } & Elevation & $F_{1,138}=0.748$ & \\
\hline & Side & $F_{1,138}=23.345^{* * *}$ & 6.51 \\
\hline & Sex & $F_{1,138}=146.893^{* * *}$ & 40.98 \\
\hline & Side $\times$ Elevation & $F_{1,138}=5.234^{*}$ & 1.46 \\
\hline & Body size & $F_{1,133}=0.912$ & \\
\hline \multirow[t]{4}{*}{ Tarsus length } & Elevation & $F_{1,151}=24.936^{* * *}$ & 17.22 \\
\hline & Side & $F_{1,150}=3.721$ & \\
\hline & Sex & $F_{1,151}=24.936^{* * *}$ & 11.02 \\
\hline & Body size & $F_{1,133}=0.603$ & \\
\hline \multirow[t]{4}{*}{ Bill length } & Elevation & $F_{1,136}=1.879$ & \\
\hline & Side & $F_{1,135}=1.082$ & \\
\hline & Sex & $F_{1,134}=0.164$ & \\
\hline & Body size & $F_{1,137}=3.207$ & \\
\hline \multirow[t]{4}{*}{ Bill width } & Elevation & $F_{1,153}=4.945^{*}$ & 2.76 \\
\hline & Side & $F_{1,134}=0.844$ & \\
\hline & Sex & $F_{1,152}=0.144$ & \\
\hline & Body size & $F_{1,135}=2.248$ & \\
\hline \multirow[t]{5}{*}{ Bill depth } & Elevation & $F_{1,134}=18.860^{* * *}$ & 9.57 \\
\hline & Side & $F_{1,134}=21.520^{* * *}$ & 10.92 \\
\hline & Sex & $F_{1,133}=0.845$ & \\
\hline & Side $\times$ Elevation & $F_{1,134}=12.626^{* * *}$ & 6.40 \\
\hline & Body size & $F_{1,134}=7.448^{* *}$ & 3.78 \\
\hline
\end{tabular}

Table 1 Variation in morphological traits of Glyphorynchus spirurus. Backward eliminated parameters in a generalized linear model are shown, with the parameters kept in the final model shown in bold face. The variable 'side' corresponds to the east or west side of the Andes

${ }^{*} P<0.05,{ }^{* *} P<0.01,{ }^{* * *} P<0.001$.

Table 2 Mitochondrial DNA (ND2 gene) uncorrected pairwise genetic distances (above diagonal), within-population genetic distances (along diagonal, italic), and $F_{\mathrm{ST}}$-values (below diagonal) among Glyphorynchus spirurus populations east (SR, HO, CU, SA, MZ, JS, PA, TI and YA) and west of the Andes (SU, RC, BA, PJ, MA, BI and LA). See Fig. 1 and Table 1 for sampling site codes

\begin{tabular}{lrrrrrrrrrrrrrrrrr}
\hline & \multicolumn{1}{l}{ SR } & HO & CU & \multicolumn{1}{l}{ SA } & MZ & JS & PA & TI & YA & SU & RC & BA & PJ & MA & BI & LA \\
\hline SR & 2.20 & 2.10 & 1.87 & 2.24 & 3.15 & 2.00 & 5.99 & 1.76 & 1.80 & 44.96 & 44.80 & 45.60 & 44.93 & 44.80 & 44.54 & 44.60 \\
HO & 0.24 & 1.26 & 1.32 & 1.12 & 2.65 & 0.86 & 5.96 & 1.11 & 1.14 & 44.89 & 44.72 & 45.52 & 44.86 & 44.72 & 44.46 & 44.52 \\
CU & 0.11 & 0.04 & 1.27 & 1.43 & 2.48 & 1.18 & 5.65 & 1.04 & 1.09 & 44.55 & 44.38 & 45.18 & 44.52 & 44.38 & 44.12 & 44.18 \\
SA & 0.52 & 0.17 & 0.38 & 0.59 & 2.97 & 0.33 & 6.30 & 1.31 & 1.25 & 45.59 & 45.42 & 46.22 & 45.56 & 45.42 & 45.16 & 45.22 \\
MZ & 0.11 & 0.25 & 0.14 & 0.54 & 3.50 & 2.75 & 6.62 & 2.16 & 2.19 & 44.39 & 44.15 & 44.88 & 44.25 & 44.30 & 43.91 & 43.75 \\
JS & 0.40 & 0.08 & 0.31 & -0.04 & 0.36 & 0.00 & 6.07 & 1.06 & 1.00 & 45.36 & 45.20 & 46.00 & 45.33 & 45.20 & 44.94 & 45.00 \\
PA & -0.03 & 0.15 & 0.05 & 0.25 & -0.03 & 0.07 & 9.18 & 5.51 & 5.62 & 43.44 & 43.24 & 44.00 & 43.36 & 43.32 & 42.99 & 42.93 \\
TI & 0.25 & 0.06 & 0.01 & 0.47 & 0.18 & 0.46 & 0.10 & 0.81 & 0.83 & 44.37 & 44.19 & 44.97 & 44.31 & 44.23 & 43.93 & 43.94 \\
YA & 0.17 & 0.03 & -0.01 & 0.42 & 0.08 & 0.42 & 0.05 & -0.04 & 0.93 & 44.50 & 44.30 & 45.06 & 44.42 & 44.38 & 44.05 & 44.00 \\
SU & 0.95 & 0.97 & 0.96 & 0.98 & 0.95 & 0.97 & 0.86 & 0.97 & 0.96 & 2.04 & 2.53 & 2.32 & 2.79 & 1.78 & 1.56 & 1.45 \\
RC & 0.94 & 0.97 & 0.96 & 0.98 & 0.93 & 0.96 & 0.83 & 0.97 & 0.96 & 0.06 & 2.80 & 2.20 & 2.27 & 2.48 & 2.14 & 1.80 \\
BA & 0.95 & 0.97 & 0.97 & 0.98 & 0.94 & 0.97 & 0.82 & 0.98 & 0.97 & 0.07 & 0.17 & 2.33 & 2.25 & 2.30 & 1.94 & 1.50 \\
PJ & 0.95 & 0.97 & 0.96 & 0.98 & 0.93 & 0.96 & 0.83 & 0.97 & 0.96 & 0.17 & -0.21 & -0.12 & 2.67 & 2.77 & 2.42 & 2.00 \\
MA & 0.96 & 0.97 & 0.97 & 0.98 & 0.95 & 0.97 & 0.86 & 0.97 & 0.97 & 0.07 & 0.11 & 0.13 & 0.22 & 1.78 & 1.49 & 1.60 \\
BI & 0.97 & 0.97 & 0.97 & 0.98 & 0.97 & 0.98 & 0.88 & 0.98 & 0.98 & 0.00 & 0.17 & 0.20 & 0.29 & 0.04 & 1.11 & 0.81 \\
LA & 0.98 & 0.98 & 0.98 & 0.99 & 0.98 & 1.00 & 0.86 & 0.99 & 0.99 & 0.25 & 0.34 & 0.41 & 0.40 & 0.41 & 0.23 & 0.00 \\
\hline
\end{tabular}

the west when samples were grouped into Andean (SU, $\mathrm{RC}, \mathrm{BA}, \mathrm{PJ}$ and MA) and Coastal Range (BI and LA) groups $\left(\Phi_{\mathrm{ct}}=5.30 \%, P=0.274 ; \Phi_{\mathrm{sc}}=8.38 \%, P=0.008\right.$; $\left.\Phi_{\mathrm{st}}=86.32 \%, P=0.013\right)$. However, despite the low $\Phi_{\mathrm{ct}}$ value, an exact test of population differentiation was significant for the west Andes vs. Coastal Range comparison $(P<0.001)$, which is consistent with the significant $F_{\mathrm{ST}}$-value reported above. 


\begin{tabular}{lrrll}
\hline & $\begin{array}{l}\text { Elevation } \\
\text { Site }\end{array}$ & \multicolumn{1}{l}{$h$} & \multicolumn{1}{l}{} \\
\hline East of Andes & & 102 & $0.792 \pm 0.028$ & $0.0042 \pm 0.0025$ \\
$\quad$ Tiputini (TI) & 400 & 16 & $0.600 \pm 0.127$ & $0.0013 \pm 0.0011$ \\
Yasuní (YA) & 400 & 8 & $0.750 \pm 0.139$ & $0.0015 \pm 0.0013$ \\
Pañacocha (PA) & 400 & 15 & $0.791 \pm 0.105$ & $0.0144 \pm 0.0079$ \\
Jatun Sacha (JS) & 400 & 4 & $0.000 \pm 0.000$ & $0.0000 \pm 0.0000$ \\
Miazal (MZ) & 300 & 4 & $0.500 \pm 0.265$ & $0.0055 \pm 0.0042$ \\
Sangay (SA) & 1375 & 18 & $0.451 \pm 0.117$ & $0.0009 \pm 0.0009$ \\
Cumandá (CU) & 1323 & 11 & $0.855 \pm 0.066$ & $0.0020 \pm 0.0015$ \\
Hollín (HO) & 1320 & 21 & $0.786 \pm 0.075$ & $0.0020 \pm 0.0014$ \\
San Rafael (SR) & 1300 & 5 & $0.800 \pm 0.164$ & $0.0034 \pm 0.0026$ \\
West of Andes & & 60 & $0.795 \pm 0.030$ & $0.0028 \pm 0.0018$ \\
Sacha Urco-Mindo (SU) & 1249 & 11 & $0.818 \pm 0.083$ & $0.0044 \pm 0.0022$ \\
Río Cinto-Mindo (RC) & 1398 & 5 & $0.900 \pm 0.161$ & $0.0032 \pm 0.0032$ \\
Bancos (BA) & 750 & 4 & $0.833 \pm 0.222$ & $0.0037 \pm 0.0030$ \\
Pachijal (PJ) & 650 & 6 & $0.800 \pm 0.172$ & $0.0042 \pm 0.0030$ \\
Maldonado (MA) & 405 & 10 & $0.733 \pm 0.120$ & $0.0028 \pm 0.0020$ \\
Bilsa (BI) & 650 & 16 & $0.642 \pm 0.103$ & $0.0017 \pm 0.0013$ \\
Loma Alta (LA) & 490 & 8 & $0.000 \pm 0.000$ & $0.0000 \pm 0.0000$ \\
\hline
\end{tabular}

Table 3 Sample sizes, elevation, mtDNA haplotypic diversity $(h)$ and nucleotide diversity $(\pi)$ per sampling site
Variation in the ND2 gene was selectively neutral as determined by a McDonald-Kreitman test comparing eastern and western lineages $(\mathrm{SF}=13, \mathrm{SP}=45, \mathrm{RF}=6$, $\mathrm{RP}=9$, Fisher exact test, $P=0.195$; excluding 'G-clade': $\mathrm{SF}=27, \mathrm{SP}=21, \mathrm{RF}=6, \mathrm{RP}=8$, Fisher exact test, $P=0.544)$. Fu's $F_{\mathrm{s}}$-test revealed evidence of a past population expansion east of the Andes $\left(F_{\mathrm{s}}=-8.167\right.$, $P=0.006)$ but not on the west side $\left(F_{\mathrm{s}}=-0.523\right.$, $P=0.446)$.

AFLP variation. One-hundred and thirty-six variable AFLP loci were unambiguously scored for 178 individuals. Each of the three primer pairs used (E-tag/M-cga, E-tgc/M-cga and E-tgc/M-cgt) contributed a similar number of markers (49, 41 and 46 respectively). The correlation between fragment sizes and allele frequencies was not significant (Pearson correlation coefficient $=0.0178$, $P=0.837$ ), suggesting that band size did not bias the pattern of polymorphism (Vekemans et al. 2002).

Population differentiation in AFLP loci across the Andes was high (mean $F_{\mathrm{ST}}=0.41, \mathrm{SD}=0.05$ ), yet low among sites in the east (mean $F_{\mathrm{ST}}=0.04, \mathrm{SD}=0.03$ ) and west side of the Andes (mean $F_{\mathrm{ST}}=0.03$, $\mathrm{SD}=0.03$ ) (Table 4). However, the coastal sites (Loma Alta and Bilsa) showed higher $F_{\mathrm{ST}^{-}}$-values with respect to the west-Andean populations (0.18 and 0.09 respectively) (Table 4).

An analysis of genetic structure using Bayesian inference in the program Structure 2.2 yielded an optimal value of $K=2$, which corresponds to the eastern and western slopes of the Andes (Fig. 5A). A subsequent analysis within each side yielded again optimal values of $K=2$ in both the east and the west. In the west, the two clusters corresponded to the coastal range populations (BI and LA) and the west Andean populations, whereas in the east no clear geographical structure was detected (Fig. 5B). Optimal values of $K$ were obtained from the method by Evanno et al. (2005) and the corresponding plots of $\Delta K$ vs. $K$ are shown on Fig. S1.

A plot of the first two principal coordinates in a principal coordinate analysis identified not only the main east-west partition (Fig. 6A), but also considerable structure within the west side, with the two coastal range populations (Bilsa and Loma Alta) appearing separated not only from the West Andean populations but also from each other (Fig. 6B). Again, no significant structure was apparent in the east side (Fig. 6C). A Mantel test revealed a slight effect of isolation by distance in driving population divergence on the west side of the Andes $(r=0.147, P=0.003)$ but not on the east side $(r=-0.044, P=0.998)$.

Adaptive genetic variation. Plots of $F_{\mathrm{ST}}$ vs. heterozygosity (not shown) failed to detect significant outliers among the 136 AFLP loci when comparing populations across habitats (foothills vs. lowlands). This indicates that none of the markers used was identified as being under selection or linked to a marker under selection.

\section{Combined morphological and genetic analysis}

Bivariate plots of morphological divergence in tarsus length against genetic divergence showed that population comparisons across the altitudinal gradient (foothills vs. lowlands) tended to be more divergent than foothillfoothill and lowland-lowland comparisons, irrespective 


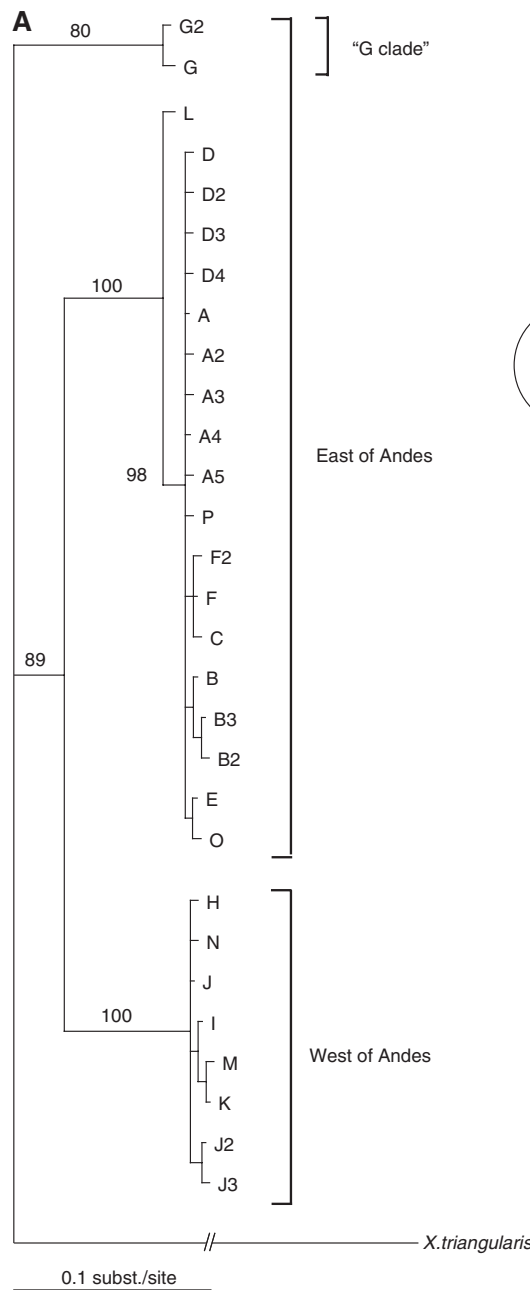

B<smiles>[C+]1CCCC1</smiles>
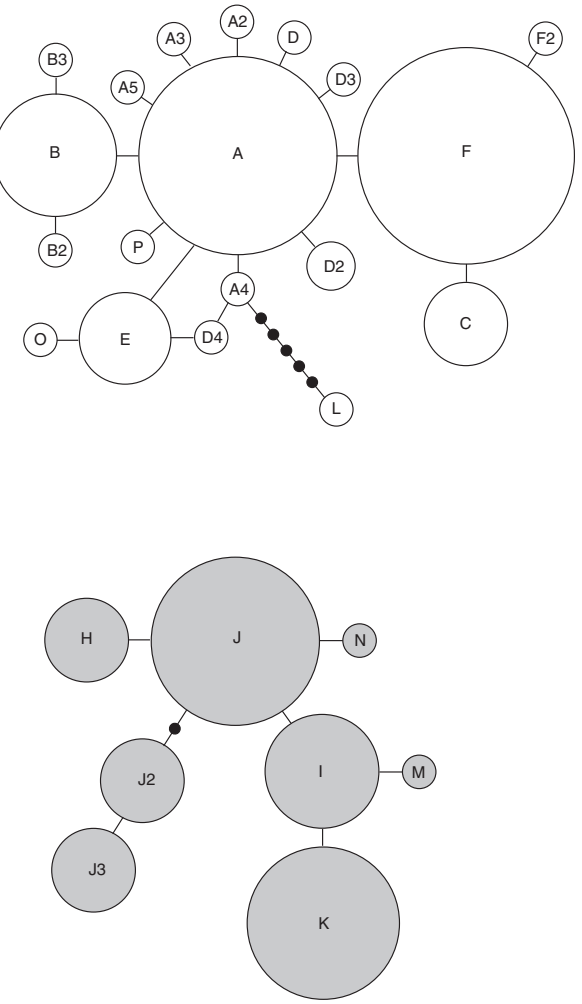

Fig. 3 Phylogenetic relationships among mtDNA haplotypes. (A) A phylogenetic tree based on Bayesian inference. Values above branches indicate the probability of node support if $>95 \%$. (B) Median-joining networks of haplotypes corresponding to each main mtDNA clade in the east (white circles) and west side of the Andes (shaded circles). Each circle represents a haplotype and its size is proportional to its total frequency. Branches represent a single nucleotide change and black circles correspond to unsampled haplotypes.

of the magnitude of genetic divergence (Fig. 7). This analysis was confined to populations in the east side of the Andes, where sufficient sampling sites were available that could be clearly assigned to foothill or lowland habitat. The average morphological divergence value in foothill-lowland comparisons was 1.01, in contrast to average values for foothill-foothill and lowland-lowland comparisons of 0.36 and 0.28 respectively.

\section{Discussion}

\section{Genetic structure}

Genetic variation in the mitochondrial and genomic markers surveyed is consistent with the role of genetic drift in differentiating populations of Glyphorynchus spirurus across major geographical barriers to gene flow.
As in other rainforest bird species (Chaves et al. 2007; Nyári 2007) the Andean cordillera represents an impassable barrier for G. spirurus as indicated by the complete geographical separation of eastern and western lineages based on both mtDNA and AFLP data. Divergence time between the two lineages is estimated at 3.21-0.81 Ma when applying a range of molecular clock calibrations for mtDNA coding regions [2.1\% per Myr (Weir \& Schluter 2008) to 8.3\% (Warren et al. 2003)]. Although divergence estimates from single-locus data should be treated with caution, this estimate is consistent with the last stage of the uplift of the northern Andes in the late Pliocene, since c. 3 Myr вр (Gregory-Wodzicki 2000). However, whether the Andean uplift drove the split between existing Amazonian and trans-Andean Chocó populations, or instead the latter colonized the west side once the Andes were already 


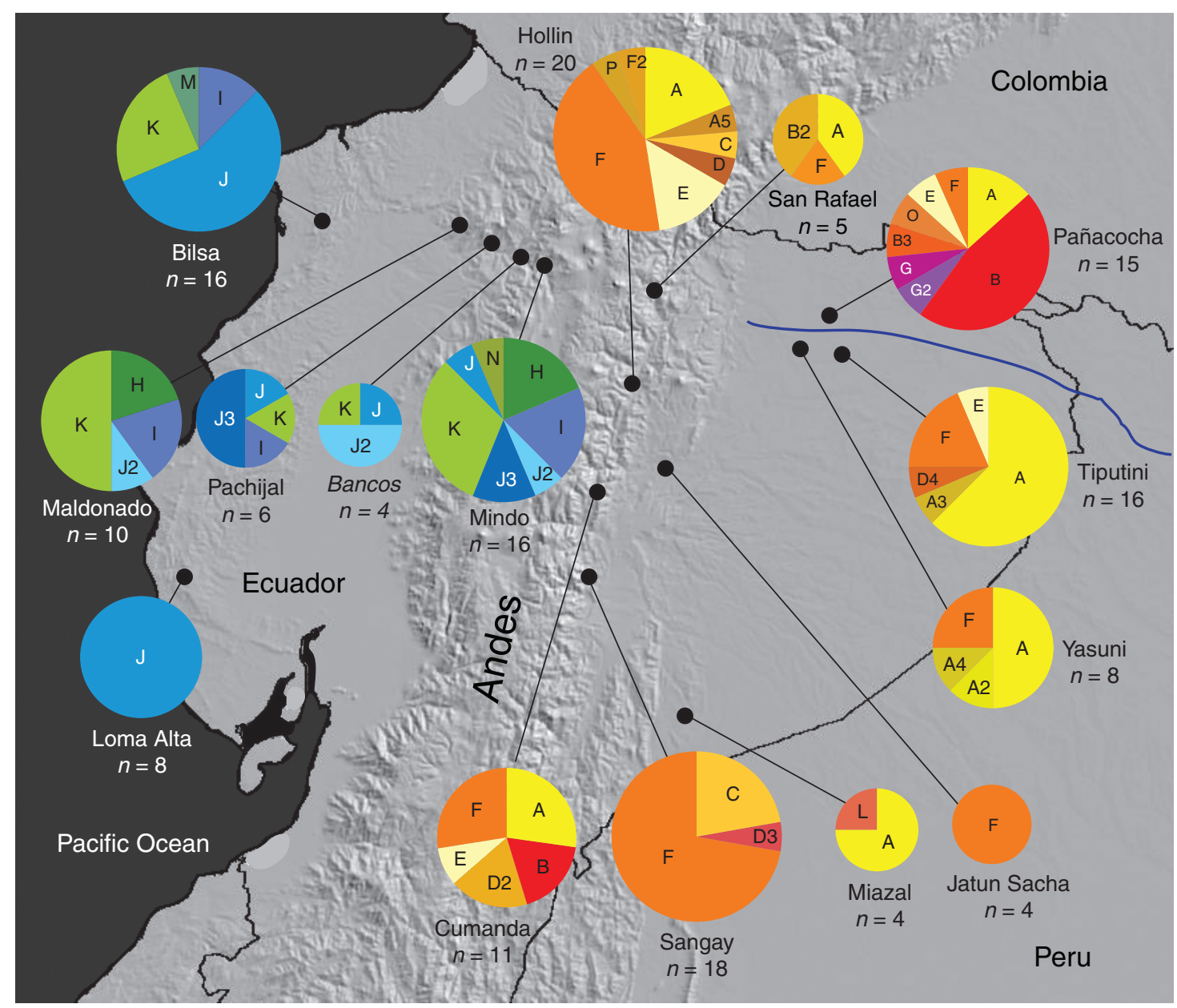

Fig. 4 Spatial distribution and diversity of mtDNA sequence variation in ND2 overlaid on a relief map of Ecuador. Pie diagrams represent haplotypes found at each sampling locality (black dots), and the size of the pie is proportional to the sample size. The Mindo site (MI) includes Río Cinto (RC) and Sacha Urco (SU). The blue line represents the Napo river.

Table 4 Nei's genetic distances (above diagonal) and $F_{\mathrm{ST}^{-}}$values (below diagonal) among populations of Glyphorynchus spirurus using AFLP data

\begin{tabular}{llllllllllllllll}
\hline & BI & LA & BA & MI & PJ & MA & CU & HO & SA & SR & JS & MZ & PA & TI & YA \\
\hline BI & 0 & 0.029 & 0.019 & 0.015 & 0.011 & 0.020 & 0.150 & 0.118 & 0.129 & 0.135 & 0.125 & 0.114 & 0.113 & 0.117 & 0.140 \\
LA & 0.164 & 0 & 0.036 & 0.041 & 0.034 & 0.040 & 0.206 & 0.174 & 0.185 & 0.185 & 0.179 & 0.171 & 0.177 & 0.174 & 0.196 \\
BA & 0.097 & 0.174 & 0 & 0.017 & 0.005 & 0.000 & 0.158 & 0.130 & 0.140 & 0.151 & 0.135 & 0.125 & 0.123 & 0.132 & 0.140 \\
MI & 0.079 & 0.197 & 0.077 & 0 & 0.001 & 0.009 & 0.162 & 0.137 & 0.145 & 0.152 & 0.140 & 0.132 & 0.130 & 0.135 & 0.159 \\
PJ & 0.060 & 0.170 & 0.023 & 0.007 & 0 & 0.003 & 0.148 & 0.122 & 0.131 & 0.134 & 0.125 & 0.119 & 0.119 & 0.122 & 0.139 \\
MA & 0.106 & 0.196 & 0.002 & 0.043 & 0.017 & 0 & 0.155 & 0.121 & 0.135 & 0.140 & 0.135 & 0.122 & 0.120 & 0.126 & 0.142 \\
CU & 0.446 & 0.533 & 0.424 & 0.435 & 0.418 & 0.428 & 0 & 0.005 & 0.007 & 0.010 & 0.000 & 0.02 & 0.015 & 0.009 & 0.006 \\
HO & 0.388 & 0.489 & 0.375 & 0.391 & 0.369 & 0.369 & 0.023 & 0 & 0.001 & 0.007 & 0.000 & 0.013 & 0.006 & 0.006 & 0.006 \\
SA & 0.400 & 0.495 & 0.385 & 0.397 & 0.378 & 0.384 & 0.033 & 0.004 & 0 & 0.006 & 0.000 & 0.011 & 0.007 & 0.004 & 0.007 \\
SR & 0.412 & 0.496 & 0.402 & 0.409 & 0.385 & 0.394 & 0.048 & 0.035 & 0.028 & 0 & 0.000 & 0.026 & 0.018 & 0.010 & 0.012 \\
JS & 0.373 & 0.465 & 0.358 & 0.371 & 0.350 & 0.367 & 0.000 & 0.000 & 0.000 & 0.000 & 0 & 0.007 & 0.008 & 0.003 & 0.000 \\
MZ & 0.365 & 0.468 & 0.353 & 0.369 & 0.351 & 0.355 & 0.087 & 0.057 & 0.047 & 0.104 & 0.027 & 0 & 0.014 & 0.012 & 0.017 \\
PA & 0.381 & 0.494 & 0.365 & 0.382 & 0.367 & 0.368 & 0.072 & 0.027 & 0.034 & 0.081 & 0.037 & 0.061 & 0 & 0.003 & 0.010 \\
TI & 0.382 & 0.484 & 0.374 & 0.384 & 0.365 & 0.374 & 0.041 & 0.030 & 0.018 & 0.046 & 0.014 & 0.054 & 0.013 & 0 & 0.007 \\
YA & 0.431 & 0.522 & 0.397 & 0.431 & 0.404 & 0.410 & 0.031 & 0.028 & 0.035 & 0.056 & 0.000 & 0.076 & 0.050 & 0.032 & 0.000 \\
\hline
\end{tabular}




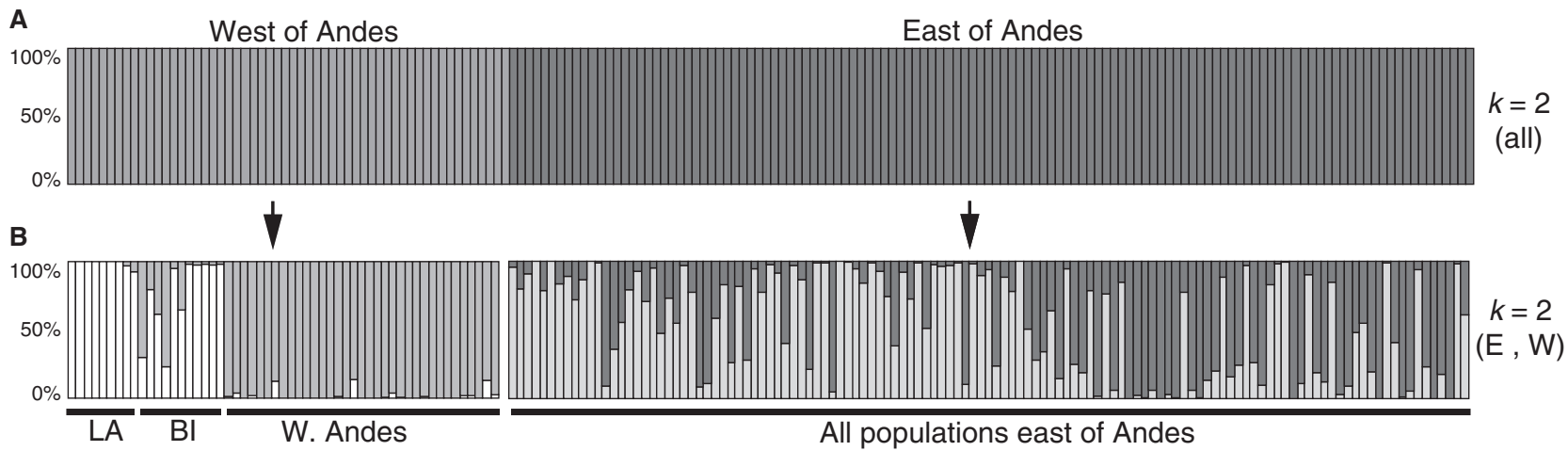

Fig. 5 (A) Posterior assignment probabilities of 178 individuals of Glyphorynchus spirurus to an optimal number of two clusters $(K=2)$ as determined by a Bayesian assignment analysis using the program Structure 2.2. (B) Each of the two clusters in (A) where reanalysed to reveal in turn two clusters on each side of the Andes. In the west, the populations of Loma Alta and Bilsa (coastal range) form a separate cluster from the west-Andean populations, whereas east of the Andes no clear pattern of structure was detected. See Fig. $S 1$ for plots of $\Delta K$ vs. $K$ showing optimal $K$-values for each analysis.
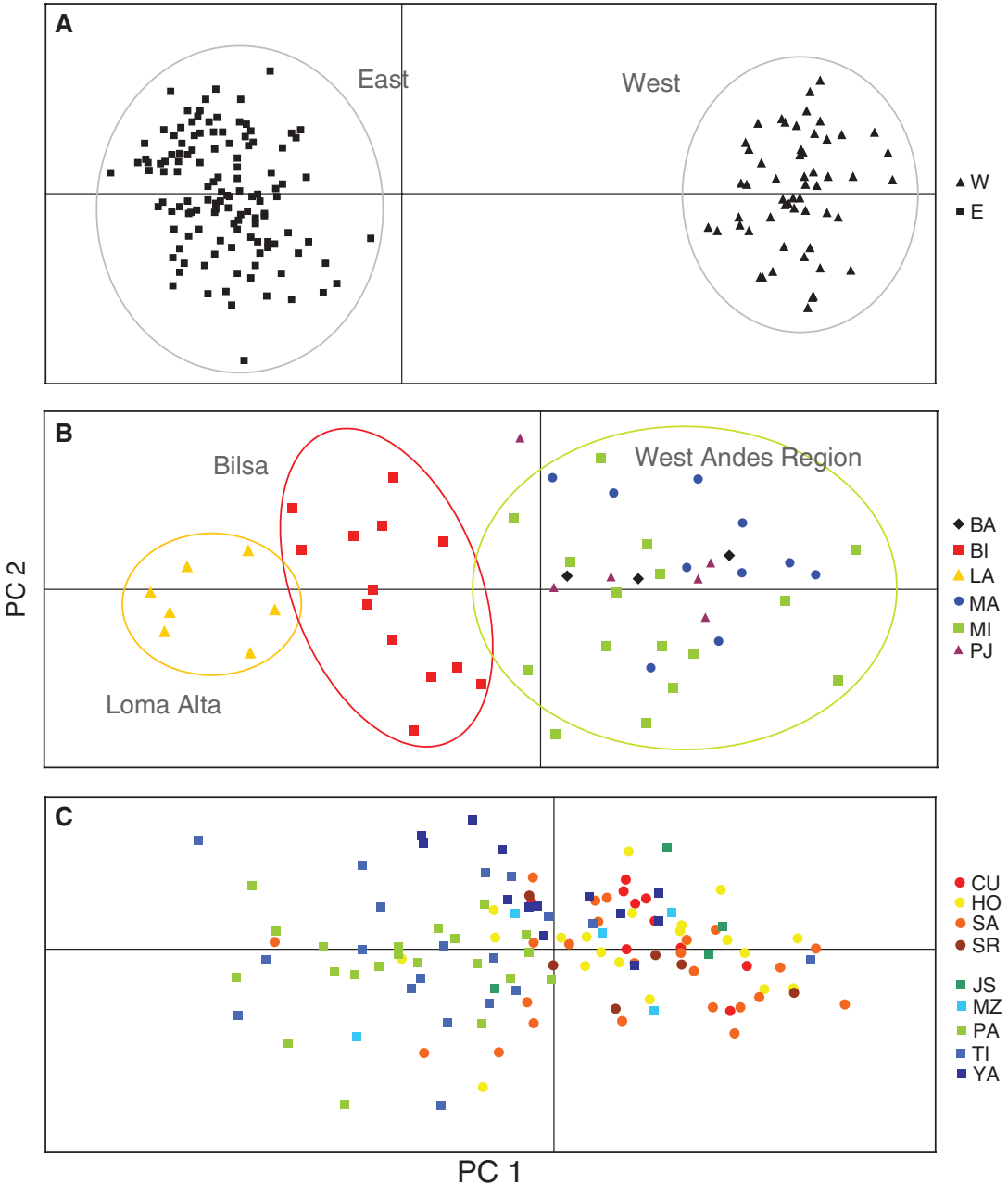

Fig. 6 Principal coordinate analysis of AFLP marker variation in Glyphorynchus spirurus populations. (A) When all individuals are included, the principal coordinate analysis reveals two main clusters corresponding to eastern and western Andean sides (first two coordinates explain $78.2 \%$ of the variance). (B) Individuals west of the Andes cluster into three main groups along the first coordinate (first two coordinates explain $44.4 \%$ of the variance). (C) Individuals east of the Andes do not show a clear pattern of spatial structure (first two coordinates explain $37.5 \%$ of the variance). See Fig. 1 for sampling site codes. The Mindo site (MI) includes Río Cinto (RC) and Sacha Urco (SU) localities. present, remains unclear. The presence of the highly divergent 'G-clade' east of the Andes in western Amazonia is consistent with the pattern previously reported by Marks et al. (2002) in their range-wide phylogeographical survey, which reveals the existence of old intraspecific lineages in close proximity, or even sympatry, within Amazonia. This pattern probably reflects a long history of isolation in allopatry followed 


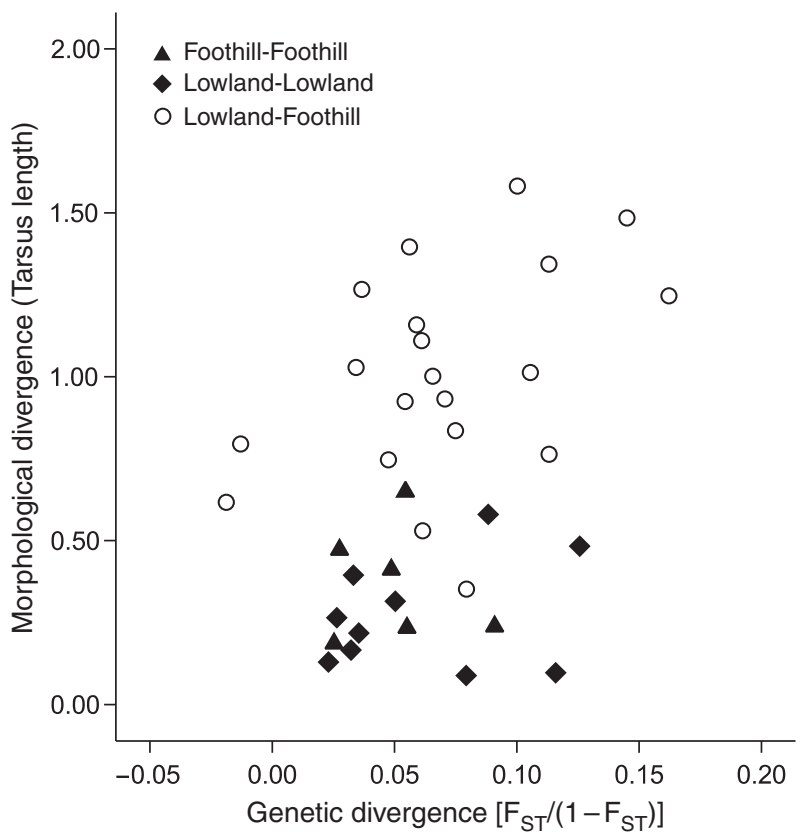

Fig. 7 Plot of morphological divergence (Euclidean distances of normalized tarsus length) against genetic divergence $\left[F_{\mathrm{ST}} /\left(1-F_{\mathrm{ST}}\right)\right]$ among wedge-billed woodcreeper populations east of the Andes. Pairwise population comparisons are classified as either a within-habitat comparison (foothill-foothill and lowland-lowland, black symbols) or across habitats (foothilllowlands, empty circles).

by secondary contact, and suggests that lineage divergence in the species can take place in the absence of major orographical barriers like the Andes.

Amplified fragment length polymorphism markers revealed population differentiation driven by geographical distance and isolation west of the Andes that was not detectable using mtDNA sequence data. Both coastal range populations (Bilsa and Loma Alta) are genetically isolated from sites on the west-Andean slope. As remote-sensing data revealed in a previous study (Buermann et al. 2008), the Loma Alta site in the Chongón-Colonche Mountains is disjunct from the rest of the species distribution in Ecuador. The Bilsa population in the Mache-Chindul Mountains is considerably less isolated from Andean populations by areas of low suitability (Buermann et al. 2008), yet intervening areas have likely become disjunct from suitable habitat in the Andean foothills due to the widespread conversion of forest to agriculture in historical times.

\section{Morphological divergence in the presence of gene flow and implications for speciation}

We found a significant amount of morphological divergence among populations of G. spirurus along altitudinal gradients despite a pattern of genetic variation that is consistent with high levels of gene flow. Morphological variation appears to be influenced by environmental factors along the altitudinal gradient, and the fact that the elevation effect on morphology is similar on both Andean slopes suggests that parallel adaptive divergence evolved independently in two subspecific lineages of G. spirurus.

The increase in overall body size with altitude is consistent with Bergmann's rule, which has been widely documented in birds and suggested to be an adaptation to reduce the surface-to-volume ratio in colder climates (Zink \& Remsen 1986). Moreover, when controlling for body size, tarsus length and bill shape (but not bill length) are significantly and positively correlated with elevation and moss abundance on tree trunks. Ecomorphological studies have demonstrated the importance of tarsometatarsus length for different forms of locomotion and foraging postures (Norberg 1979; Leisler \& Winkler 1985; Moreno \& Carrascal 1993; Zeffer et al. 2003). Biomechanical analyses show that species that climb trees by hopping upwards on trunks have shorter tarsi in order to minimize the distance between the centre of mass and the trunk, and to reduce the muscle forces needed for flexion and extension of the leg during clinging to a vertical surface (Norberg 1979; Zeffer \& Norberg 2003). The presence of moss on tree trunks might favour slightly longer tarsi to reduce friction during climbing, thus enhancing performance, and the possibility of grabbing onto the moss instead of just clinging to the bark may reduce selection for short tarsi, thus increasing step length. However, in the absence of proper biomechanical analysis or performance experiments (at present beyond the scope of our study), the extent to which differences in tarsus length are adaptive and the specific fitness advantage of varying tarsus length along the altitudinal gradient remains untested. In addition, although the increase in tarsus length with elevation on the eastern slope of the Andes is clear, the pattern is less marked on the western slope. This could be due in part to smaller sample sizes but also the role of coastal mountains (relatively more humid than the Andes at a given altitude) in affecting the relationship. Further sampling and the addition of other environmental variables are necessary to clarify fully this issue.

In contrast to foraging-related traits, wing and tail length are associated with tree density, suggesting that flight morphology may be impacted by flight distances among trees rather than habitat type per se. Flight mechanics predict that long wings are favoured for fast, direct flight, whereas shorter and more rounded wings confer manoeuvrability in denser environments (Rayner 1988; Winkler \& Leisler 1992). Selection on wing length in forests of different tree density could affect fitness by optimizing flight efficiency and energetic cost during 
foraging. Again, proper tests of performance should be carried out to test this hypothesis and our correlative evidence should be interpreted with caution.

Our data suggest that despite high levels of gene flow, selection may be sufficiently strong to cause morphological divergence in parapatric populations, a result that is consistent with a central component of the divergence-with-gene-flow model of diversification (Rice \& Hostert 1993). We found no morphological differences between same-habitat individuals from populations on either side of the Andes, even though eastern and western lineages diverged between 1 and $3 \mathrm{Ma}$. Yet within each lineage we found significant differences between individuals in lowland and foothill populations. Thus, morphological divergence in G. spirurus appears to be driven more by habitat differences than geographical isolation and suggests that selection in parapatry may be more important than isolation in causing adaptive divergence in morphology. Other studies in the wet tropics have shown a similar lack of differentiation in morphology despite large genetic differences (Schneider \& Moritz 1999; Smith et al. 2001, 2005).

The role of habitat type in structuring bird communities along altitudinal gradients has been documented in tropical (Terborgh 1971; Price 1991) and temperate latitudes (Able \& Noon 1976), and it has been shown that ecotones often correspond to species distribution limits driven by changes in selective regimes. Phenotypic divergence along altitudinal gradients has been documented in other bird species (Endler 1977; Price 1991; Soobramoney et al. 2005; Kleindorfer et al. 2006; Ryan et al. 2007; McCormack \& Smith 2008), yet few studies have simultaneously examined phenotypic variation and patterns of gene flow using molecular data. The pattern of adaptive morphological variation observed in G. spirurus is consistent with expectations of a recent niche expansion (McCormack \& Smith 2008) as the species colonized montane forests from lowland tropical forests, where the species is most common throughout its range.

Our conclusions rest on two assumptions regarding the evolutionary mechanisms underlying the observed divergence: (i) that divergent natural selection in different habitats has caused the differences in traits and (ii) that the morphological traits studied are heritable and not subject to substantial phenotypic plasticity. Given that our evidence is correlative and in the absence of experimental data, our conclusions should be treated with caution. The parallel pattern of trait divergence on both Andean sides, the fact that some but not all traits show a divergent trend, and that the effects detected are consistent with functional predictions, suggest that morphological variation is the product of directional selection. However, the extent to which phenotypic plasticity instead of selection on heritable variation has contributed to the morphological differences found, is unknown. Although the traits used in this study show typically high heritability (Grant 1986; Schluter \& Smith 1986; Boag \& van Noordwijk 1987), and some of them have been shown to be genetically controlled in common-garden experiments (Rasner et al. 2004; Bears et al. 2008) in passerine birds, determining the role of maternal effects and other environmental effects on the morphology of G. spirurus will require further research.

Whether the microevolutionary divergence described here will lead to macroevolutionary processes such as speciation depends on several additional factors related to both the long-term stability of the environmental differences, and the behaviour, physiology and population dynamics of the birds themselves. These factors are difficult to predict, and whether the incipient adaptive variation detected here will lead to reproductive isolation is uncertain. Nevertheless, a growing number of studies suggest divergence-with-gene-flow speciation may be common (Nosil 2008), and our results highlight the importance of adaptive processes in population divergence and potentially rainforest diversification.

Our findings also underscore the importance of ecological transition zones as areas to be targeted for the preservation of adaptive processes. Specifically, they point at the lowland-foothill transition in the Andes as an area of particular conservation concern for the preservation of an unparalleled biodiversity as well as the processes that generate and maintain it.

\section{Acknowledgements}

For brave assistance in the field, we thank Gabriela Castañeda, Jaime Chaves, Juan Fernando Freile, Tatiana Santander, Brandt T. Ryder, Daniela Gross, Juan Diego Ortiz, Orfa Rodríguez, María Fernanda Salazar, Suzanne Tomassi, John McCormack, Brenda Larison, Luis Carrasco, Marcelo Tobar, Jordan Karubian, the Timpe family and the communites of Miazal, Loma Alta and Nueva Esperanza. For assistance in the laboratory, we thank Navi Timber, Daniel Greenfield and John Pollinger. Thanks to U.M. Norberg and L.M. Carrascal for fruitful discussions on woodcreeper ecomorphology. Two anonymous reviewers and the associate editor provided insightful comments on previous versions of the manuscript. Funding was provided by grants from NSF (IRCEB9977072 to T.B.S. and R.K.W.) and NASA (IDS/03-0169-0347 to T.B.S.)

\section{References}

Able KP, Noon BR (1976) Avian community structure along elevational gradients in the northeastern United States. Oecologia (Berlin), 26, 275-294.

Aleixo A (2004) Historical diversification of a terra-firme forest bird superspecies: a phylogeographic perspective on the role 
of different hypotheses of Amazonian diversification. Evolution, 58, 1303-1317.

Avise JC (2000) Phylogeography: The History and Formation of Species. Harvard University Press, Cambridge, Massachusetts.

Bears H, Drever MC, Martin K (2008) Comparative morphology of dark-eyed juncos Junco hyemalis breeding at two elevations: a common aviary experiment. Journal of Avian Biology, 39, 152-162.

Beaumont MA, Nichols RA (1996) Evaluating loci for use in the genetic analysis of population structure. Proceedings of the Royal Society of London. Series B, Biological Sciences, 263, 16191626.

Boag PT, van Noordwijk AJ (1987) Quantitative genetics. In: Avian Genetics: A Population and Ecological Approach (eds Buckley PA, Cooke F), pp. 45-78. Academic Press, New York.

Bonin A, Bellemain E, Bronken Eidesen P et al. (2004) How to track and assess genotyping erros in population genetics studies. Molecular Ecology, 13, 3261-3273.

Bonin A, Taberlet P, Miaud C, Pompanon F (2006) Explorative genome scan to detect candidate loci for adaptation along a gradient of altitude in the common frog (Rana temporaria). Molecular Biology and Evolution, 23, 773-783.

Brumfield RT (2005) Mitochondrial variation in Bolivian populations of the Variable Antshrike (Thamnophilus caerulescens). Auk, 122, 414-432.

Brumfield RT, Jernigan RW, McDonald DB, Braun MJ (2001) Evolutionary implications of divergent clines in an avian (Manacus: Aves) hybrid zone. Evolution, 55, 2070-2087.

Buermann W, Saatchi S, Smith TB et al. (2008) Predicting species distrubutions across the Amazonian and Andean regions using remote sensing data. Journal of Biogeography, 35, 1160-1176.

Cabanne GS, Santos FR, Miyaki CY (2007) Phylogeography of Xiphorhynchus fuscus (Passeriformes, Dendrocolaptidae): vicariance and recent demographic expansion in southern Atlantic forest. Biological Journal of the Linnean Society, 91, 7384.

Cadena CD, Klicka J, Ricklefs RE (2007) Evolutionary differentiation in the Neotropical montane region: molecular phylogenetics and phylogeography of Buarremon brushfinches (Aves, Emberizidae). Molecular Phylogenetics and Evolution, 44, 993-1016.

Chaves JA, Pollinger JP, Smith TB, LeBhun G (2007) The role of geography and ecology in shaping the phylogeography of the speckled hummingbird (Adelomyia melanogenys) in Ecuador. Molecular Phylogenetics and Evolution, 43, 795-807.

Cheviron ZA, Capparella AP, Vuilleumier F (2005) Molecular phylogenetic relationships among the Geositta Miners (Furnariidae) and biogeographic implications for avian speciation in Fuego-Patagonia. Auk, 122, 158-174.

Coyne JA, Orr HA (2004) Speciation. Sinauer Associates, Inc., Sunderland, Massachusetts.

Dingle C, Lovette IJ, Canaday C, Smith TB (2006) Elevational zonation and the phylogenetic relationships of the Henicorhina woodwrens. Auk, 123, 119-134.

Endler JA (1977) Geographic Variation, Speciation and Clines. Princeton University Press, Princeton, New Jersey.
Endler JA (1982) Problems in distinguishing historical from ecological factors in biogeography. American Zoologist, 22, 441-452.

Evanno G, Regnaut S, Goudet J (2005) Detecting the number of clusters of individuals using the software Structure: a simulation study. Molecular Ecology, 14, 2611-2620.

Excoffier L, Smouse PE, Quattro JM (1992) Analysis of molecular variance inferred from metric distances among DNA haplotypes: application to human mitochondrial DNA restriction data. Genetics, 131, 479-491.

Excoffier L, Laval G, Schneider S (2005) Arlequin ver. 3.0: an integrated software package for population genetics data analysis. Evolutionary Bioinformatics Online, 1, 47-50.

Fjeldså J, Lovett JC (1997) Geographical patterns of old and young species in African forest biota: the significance of specific montane areas as evolutionary centres. Biodiversity and Conservation, 6, 325-346.

Forster M, Forster P, Watson J (2007) NETWORK (version 4.2.0.1): A software for population genetics data analysis. Fluxus Technology Ltd., Clare, Suffolk.

Fridolfsson AK, Ellegren H (1999) A simple and universal method for molecular sexing of non-ratite birds. Journal of Avian Biology, 30, 116-121.

Fu YX (1997) Statistical neutrality of mutations against population growth, hitchhiking and background selection. Genetics, 147, 915-925.

García-Moreno J, Fjeldså J (2000) Chronology and mode of speciation in the Andean avifauna. Bonner zoologische Monograph, 46, 25-46.

García-Moreno J, Navarro-Sigüenza A, Peterson AT, SánchezGonzález LA (2004) Genetic variation coincides with geographic structure in the common bush-tanager (Chlorospingus ophthalmicus) complex from Mexico. Molecular Phylogenetics and Evolution, 33, 186-196.

Gentry A (1989) Speciation in tropical forests. In: Tropical Forests: Botanical Dynamics, Speciation and Diversity (eds Holm-Nielsen LB, Nielsen IC, Balslev H), pp. 1-22. Academic Press, New York.

Grant PR (1986) Ecology and Evolution of Darwin's Finches. Princeton University Press, Princeton, New Jersey.

Gregory-Wodzicki KM (2000) Uplift history of Central and Northern Andes: a review. Geological Society of America Bulletin, 112, 1091-1105.

Haffer J (1969) Speciation in amazonian forest birds. Science, 165, 131-137.

Hedrick PW (2006) Genetic polymorphism in heterogeneus environments: the age of genomics. Annual Review of Ecology and Systematics, 37, 67-93.

Hoekstra HE (2006) Genetics, development and evolution of adaptive pigmentation in vertebrates. Heredity, 97, 222-234.

Huelsenbeck JP, Ronquist F, Nielsen R, Bollback JP (2001) Bayesian inference of phylogeny and its impact on evolutionary biology. Science, 294, 2310-2314.

Kleindorfer S, Chapman TW, Winkler H, Sulloway FJ (2006) Adaptive divergence in continuous populations of the Darwin's small ground finch (Geospiza fuliginosa). Evolutionary Ecology Research, 8, 357-372.

Knowles LL, Richards CL (2005) Importance of genetic drift during Pleistocene divergence as revealed by analyses of genomic variation. Molecular Ecology, 14, 4023-4032. 
Knox EB, Palmer JD (1995) Chloroplast DNA variation and the recent radiation of giant senecios (Asteraceae) on the tall mountains of Eastern Africa. Proceedings of the National Academy of Sciences of the United States of America, 92, 1034910353.

Leisler B, Winkler H (1985) Ecomorphology. Current Ornithology, 2, 155-186.

Lynch M, Milligan BG (1994) Analysis of population genetic structure with RAPD markers. Molecular Ecology, 3, 91-99.

Marks BD, Hackett SJ, Capparella AP (2002) Historical relationships among Neotropical lowland forest areas of endemism as determined by mitochondrial DNA sequence variation within the Wedge-billed Woodcreeper (Aves: Dendrocolaptidae: Glyphorynchus spirurus). Molecular Phylogenetics and Evolution, 24, 153-167.

Mayr E, O'Hara RJ (1986) The biogeographical evidence supporting the Pleistocene forest refuge hypothesis. Evolution, 40, 55-67.

McCormack JE, Smith TB (2008) Niche expansion leads to small-scale adaptive divergence along an elevation gradient in a medium-sized passerine bird. Proceedings of the Royal Society of London B. Series B, Biological Sciences, 275, 21552164.

McDonald JH, Kreitman M (1991) Adaptive protein evolution at the Adh locus in Drosophila. Nature, 351, 652-654.

Milá B, McCormack JE, Castañeda G, Wayne RK, Smith TB (2008) Recent postglacial range expansion drives the rapid diversification of a songbird lineage in the genus Junco. Proceedings of the Royal Society of London. Series B, Biological Sciences, 274, 2653-2660.

Moreno E, Carrascal LM (1993) Leg morphology and feeding posture in four Parus species: an experimental ecomorphological approach. Ecology, 74, 2037-2044.

Moritz C, Patton JL, Schneider CJ, Smith TB (2000) Diversification of rainforest faunas: an integrated molecular approach. Annual Review of Ecology and Systematics, 31, 533563.

Niemiller ML, Fitzpatrick BM, Miller BT (2008) Recent divergence-with-gene-flow in Tenessee cave salamanders (Plethodontidae; Gyrinophilus) inferred from gene genealogies. Molecular Ecology, 17, 2258-2275.

Norberg UM (1979) Morphology of the wings, legs and tail of three coniferous forest tits, the goldcrest and the treecreeper in relation to locomotor pattern and feeding station selection. Philosophical Transactions of the Royal Society of London. Series B, Biological Sciences, 287, 131-165.

Nosil P (2008) Speciation with gene flow could be common. Molecular Ecology, 17, 2103-2106.

Nosil P, Egan SP, Funk DJ (2008) Heterogeneous genomic differentiation between walking-stick ecotypes: 'isolation-byadaptation' and multiple roles for divergent selection. Evolution, 62, 316-336.

Nyári AS (2007) Phylogeographic patterns, molecular and vocal differentiation, and species limits in Schiffornis turdina (Aves). Molecular Phylogenetics and Evolution, 44, 154-164.

Nylander JAA (2004) MRMODELTEST v2. Evolutionary Biology Centre, Uppsala University, Uppsala. Program distributed by the author. Available from http://www.abc.se/ $\sim$ nylander/.

Ogden R, Thorpe RS (2002) Molecular evidence for ecological speciation in tropical habitats. Proceedings of the National
Academy of Sciences of the United States of America, 99, 1361213615.

Orr MR, Smith TB (1998) Ecology and speciation. Trends in Ecology and Evolution, 13, 502-506.

Peakall R, Smouse PE (2006) GENALEX 6: genetic analysis in Excel. Population genetic software for research and teaching. Molecular Ecology Notes, 6, 288-295.

Pérez-Emán J (2005) Molecular phylogenetics and biogeography of the Neotropical redstarts (Myioborus; Aves, Parulinae). Molecular Phylogenetics and Evolution, 37, 511-528.

Petren K, Grant PR, Grant BR, Keller Lf (2005) Comparative landscape genetics and the adaptive radiation of Darwin's finches: the role of peripheral isolation. Molecular Ecology, 14, 2943-2957.

Price TD (1991) Morphology and ecology of breeding warblers along an altitudinal gradient in Kashmir, India. Journal of Animal Ecology, 60, 643-664.

Pritchard JK, Wen W (2004) Documentation for Structure software: version 2. Available from http://pritch.bsd. uchicago.edu.

Pritchard JK, Stephens M, Donnelly P (2000) Inference of population structure using multilocus genotype data. Genetics, 155, 945-959.

Puebla-Olivares F, Bonaccorso E, Espinosa de los Monteros A et al. (2008) Speciation in the Emerald Toucanet (Aulachorhynchus prasinus) complex. Auk, 125, 39-50.

Pyle P (1997) Identification Guide to North American Birds. Part I. Slate Creek Press, Bolinas, California.

Rambaut D, Drummond A (2003) Tracer v. 1.3. Available from http://tree.bio.ed.ac.uk/software/tracer.

Ramos-Onsins SE, Rozas J (2002) Statistical properties of new neutrality tests against population growth. Molecular Biology and Evolution, 19, 2092-2100.

Rasner CA, Yeh P, Eggert LS et al. (2004) Genetic and morphological evolution following a founder event in the dark-eyed junco, Junco hyemalis thurberi. Molecular Ecology, 13, 671-681.

Raymond M, Rousset F (1995a) An exact test for population differentiation. Evolution, 49, 1280-1283.

Raymond M, Rousset F (1995b) GENEPOP (v. 1.2): a population genetics software for exact tests and ecumenicism. Journal of Heredity, 86, 248-249.

Rayner JMV (1988) Form and function in avian flight. Current Ornithology, 5, 1-66.

Restall R, Rodner C, Lentino M (2006) Birds of Northern South America: An Identification Guide. Yale University Press, New Haven, Connecticut.

Ribera I, Vogler AP (2004) Speciation in Iberian diving beetles in Pleistocene refugia (Coleoptera, Dytiscidae). Molecular Ecology, 13, 179-193.

Rice WR, Hostert EE (1993) Laboratory experiments on speciation: what have we learned in 40 years? Evolution, 47, 1637-1653.

Ridgely RS, Greenfield PJ (2001) The Birds of Ecuador. Cornell University Press, Ithaca.

Rousset F (1997) Genetic differentiation and estimation of gene flow from F-statistics under isolation by distance. Genetics, 145, 1219-1228.

Roy MS, Da Silva JMC, Arctander P, Garcia-Moreno J, Fjeldså J (1997) The speciation of South American and African birds in montane regions. In: Avian Molecular Evolution and 
Systematics (ed. Mindell DP), pp. 325-343. Academic Press, San Diego, California.

Rozas J, Sanchez-DelBarrio JC, Messeguer X, Rozas R (2003) DnaSP, DNA polymorphism analyses by the coalescent and other methods. Bioinformatics, 19, 2496-2497.

Rundle H, Nosil P (2005) Ecological speciation. Ecology Letters, 8, 336-352.

Ryan PG, Bloomer P, Moloney CL, Grant TJ, Delport W (2007) Ecological speciation in South Atlantic island finches. Science, 315, 1420-1423.

Schluter D (2000) The Ecology of Adaptive Radiation. Oxford University Press, Oxford.

Schluter D (2001) Ecology and the origin of species. Trends in Ecology and Evolution, 16, 372-380.

Schluter D, Smith JNM (1986) Natural selection on beak and body size in the song sparrow. Evolution, 40, 221-231.

Schneider CJ, Moritz C (1999) Rainforest refugia and evolution in Australia's Wet Tropics. Proceedings of the Royal Society of London. Series B, Biological Sciences, 266, 191-196.

Schneider CJ, Smith TB, Larison B, Moritz C (1999) A test of alternative models of diversification in tropical rainforests: ecological gradients vs. rainforest refugia. Proceedings of the National Academy of Sciences of the United States of America, 96, 13869-13873.

Sehgal RNM, Jones HI, Smith TB (2005) Molecular evidence for host specificity of parasitic nematode microfilariae in some African rainforest birds. Molecular Ecology, 14, 3988-3997.

Smith T, Wayne R, Girman D, Bruford M (1997) A role for ecotones in generating rainforest biodiversity. Science, 276, 1855-1857.

Smith TB, Schneider CJ, Holder K (2001) Refugial isolation versus ecological gradients: testing alternative mechanisms of evolutionary divergence in four rainforest vertebrates. Genetica, 112-113, 383-398.

Smith TB, Calsbeek R, Wayne RK et al. (2005) Testing alternative mechanisms of evolutionary divergence in an African rain forest passerine bird. Journal of Evolutionary Biology, 18, 257-268.

Smith TB, Milá B, Grether GF et al. (2008) Evolutionary consequences of human disturbance in a rainforest bird species from Central Africa. Molecular Ecology, 17, 58-71.

Sokal RR, Rohlf FJ (1981) Biometry. The Principles and Practice of Statistics in Biological Research, 2nd edn. W. H. Freeman and Co., New York.

Soobramoney S, Downs CT, Adams NJ (2005) Morphological variation in the common fiscal (Lanius collaris) along an altitudinal gradient in southern Africa. Ostrich, 76, 130-141.

Sorenson MD, Ast JC, Dimcheff DE, Yuri T, Mindell DP (1999) Primers for a PCR-based approach to mitochondrial genome sequencing in birds and other vertebrates. Molecular Phylogenetics and Evolution, 12, 105-114.

Stotz DF, Fitzpatrick JW, Parker TA III, Moskovits DK (1996) Neotropical Birds: Ecology and Conservation. University of Chicago Press, Chicago, Illinois.

Terborgh J (1971) Distribution on environmental gradients: theory and a preliminary interpretation of distrubutional patterns in the avifauna of the Cordillera Vicabamba, Peru. Ecology, 52, 23-40.

Vekemans X, Beauwens T, Lemaire M, Roldán-Ruíz I (2002) Data from amplified fragment length polymorphism (AFLP) markers show indication of size homoplasy and of a relationship between degree of homoplasy and fragment size. Molecular Ecology, 11, 139-151.

Vos P, Hogers R, Bleeker $M$ et al. (1995) AFLP: a new technique for DNA fingerprinting. Nucleic Acids Research, 23, 4407-4414.

Warren BH, Bermingham E, Bowie RCK, Prys-Jones RP, Thébaud C (2003) Molecular phylogeography reveals island colonization history and diversification of western Indian Ocean sunbirds (Nectarinia: Nectariniidae). Molecular Phylogenetics and Evolution, 29, 67-85.

Weir JT, Schluter D (2008) Calibrating the avian molecular clock. Molecular Ecology, 17, 2321-2328.

Winkler H, Leisler B (1992) On the ecomorphology of migrants. Ibis, 134, 21-28.

Zeffer A, Norberg UM (2003) Leg morphology and locomotion in birds: requirements for force and speed during ankle flexion. Journal of Experimental Biology, 206, 1085-1097.

Zeffer A, Johansson C, Marmebro A (2003) Functional correlation between habitat use and leg morphology in birds (Aves). Biological Journal of the Linnean Society, 79, 461-484.

Zhivotovsky LA (1999) Estimating population structure in diploids with multilocus dominant DNA markers. Molecular Ecology, 8, 907-913.

Zink RM, Remsen JVJ (1986) Evolutionary processes and patterns of geographic variation in birds. In: Current Ornithology (ed. Johnston RF), pp. 1-69. Plenum Press, New York.

B.M. is a postdoctoral researcher currently at the Museo Nacional de Ciencias Naturales in Madrid, Spain, whose research focuses on mechanisms of population divergence and speciation in birds and other vertebrates by means of various approaches, including phylogeography, population genetics and ecomorphology. R.K.W. is a professor at UCLA's Department of Ecology and Evolutionary Biology, interested in applying molecular genetic techniques to address questions in population genetics, systematics, genomics and conservation genetics of vertebrates. P.F. is researcher at the Museo Nacional de Ciencias Naturales, where he focuses on behavioural ecology, population genetics and phylogeography of reptiles and birds. T.B.S. is a professor at the Department of Ecology and Evolutionary Biology and the director of the Center for Tropical Research at UCLA. He is interested in evolutionary genetics and ecology, and his research focuses on speciation mechanism, migratory connectivity, bird-parasite interactions and the conservation of tropical vertebrates.

\section{Supporting information}

Additional supporting information may be found in the online version of this article:

\section{Data S1 Sampling localities.}

Fig. S1 Plots of $\Delta K$ vs. $K$ obtained from applying the method by Evanno et al. (2005) to determine the optimal value of $K$ in our Structure analysis of genetic variation. 
Table S1 Coefficients of correlation (equivalent to factor loadings) between morphological variables used to assess structural body size and the derived principal components extracted by principal components analysis

Table S2 Variation in morphological traits of Glyphorynchus spirurus using only samples where moss data are available
Please note: Wiley-Blackwell are not responsible for the content or functionality of any supporting information supplied by the authors. Any queries (other than missing material) should be directed to the corresponding author for the article. 